ARTICLE

\title{
Selective deoxygenative alkylation of alcohols via photocatalytic domino radical fragmentations
}

Hong-Mei Guo ${ }^{1} \&$ Xuesong Wu (i) ${ }^{1 凶}$

The delivery of alkyl radicals through photocatalytic deoxygenation of primary alcohols under mild conditions is a so far unmet challenge. In this report, we present a one-pot strategy for deoxygenative Giese reaction of alcohols with electron-deficient alkenes, by using xanthate salts as alcohol-activating groups for radical generation under visible-light photoredox conditions in the presence of triphenylphosphine. The convenient generation of xanthate salts and high reactivity of sequential $\mathrm{C}-\mathrm{S} / \mathrm{C}-\mathrm{O}$ bond homolytic cleavage enable efficient deoxygenation of primary, secondary and tertiary alcohols with diverse functionality and structure to generate the corresponding alkyl radicals, including methyl radical. Moreover, chemoselective radical monodeoxygenation of diols is achieved via selective formation of xanthate salts.

\footnotetext{
${ }^{1}$ Hubei Key Laboratory of Bioinorganic Chemistry \& Materia Medica, School of Chemistry and Chemical Engineering, Huazhong University of Science and

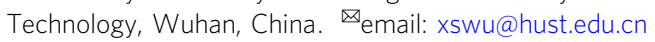


O ver the past decades, visible-light photoredox catalysis has emerged as a pre-eminent handle for the generation of alkyl radicals via single electron transfer $(\mathrm{SET})^{1-4}$. Avoiding the use of stoichiometric amounts of hazardous reagents and/or harsh reaction conditions in traditional methods such as Barton-McCombie deoxygenation (Fig. 1a $)^{5-8}$, the delivery of alkyl radicals through deoxygenation of widely occurring, naturally abundant alcohols via photoredox catalysis is strategically appealing ${ }^{9-11}$. However, the strong bonding energy and the high redox potentials of $\mathrm{C}-\mathrm{O}$ bonds have deterred the identification of general solutions in the field of photoredox catalysis ${ }^{12,13}$. To solve this problem, redox auxiliaries that include oxalates $^{14-23}$, xanthates ${ }^{19,24-27}$, carboxylates ${ }^{28-30}$, and ethers ${ }^{31}$ have emerged to transform hydroxyl groups into activating groups for alkyl radical generation via $\mathrm{C}-\mathrm{O}$ bond homolysis under visible-light photoredox conditions (Fig. 1b). Nevertheless, these approaches are generally not amenable to primary aliphatic alcohols. For example, oxalates derived from primary alcohols can only generate alkyl radicals at high temperatures, due to the relatively low reactivity of the intermediate alkoxycarbonyl radicals in losing carbon dioxide. Minisci-type reactions using pri- mary alcohols, including methanol, as alkyl precursors have been achieved under photoredox conditions via $\mathrm{a}-\mathrm{H}$ abstraction of alcohols and $\mathrm{C}-\mathrm{O}$ bond cleavage by spin-center shift elimination of water; however, these approaches are limited to the alkylation of heteroarenes ${ }^{32-34}$. In 2018, Doyle and Rovis reported the elegant deoxygenative generation of alkyl radicals directly from alcohols under visible-light photoredox conditions without preactivation steps (Fig. 1c) ${ }^{35}$. In this catalytic system, triphenylphosphine is first oxidized to a radical cation by photoexcited ${ }^{*} \operatorname{Ir}(\mathrm{III})$ catalyst. The triphenylphosphine radical cation reacts ionically with an alcohol to form a phosphoranyl radical, which proceeds through $\beta$-scission to deliver an alkyl radical. However, due to the limited substrate scope of the $\beta$-scission of phosphoranyl radical ${ }^{36-38}$, this approach is only amenable to benzylic alcohols. To date, there is not a universally applicable photoinduced deoxygenation method for aliphatic alcohols with great selectivity and efficiency, especially one that is compatible with multiple free hydroxyl groups ubiquitously present in biological molecules ${ }^{39-42}$. Therefore, a more convenient and compatible protocol for deoxygenative generation of alkyl radicals from alcohols represents unmet challenge and urgent demand.

\section{a. Barton-McCombie deoxygenation}

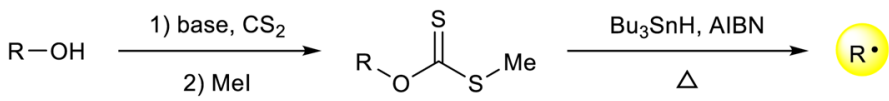

hazardous reagents \&/or harsh conditions

b. Visible-light-mediated deoxygenative radical generation from alcohols

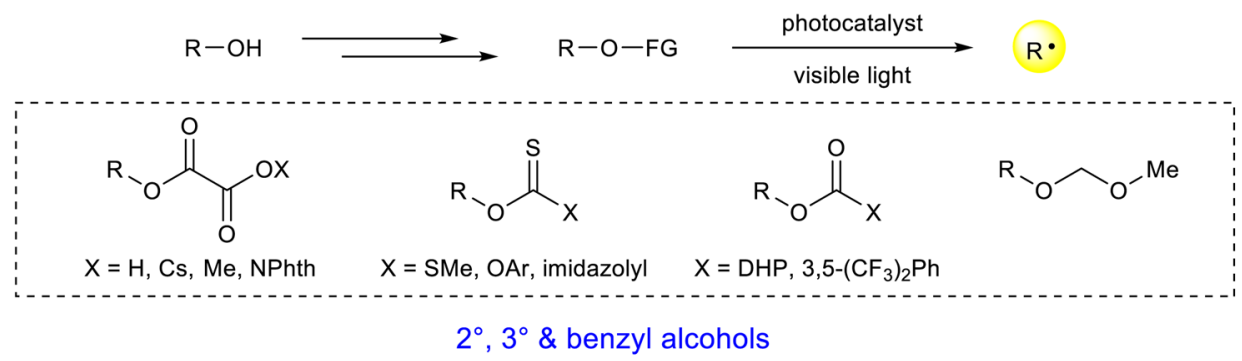

c. Visible-light-mediated deoxygenation of benzyl alcohols (Doyle, 2018)
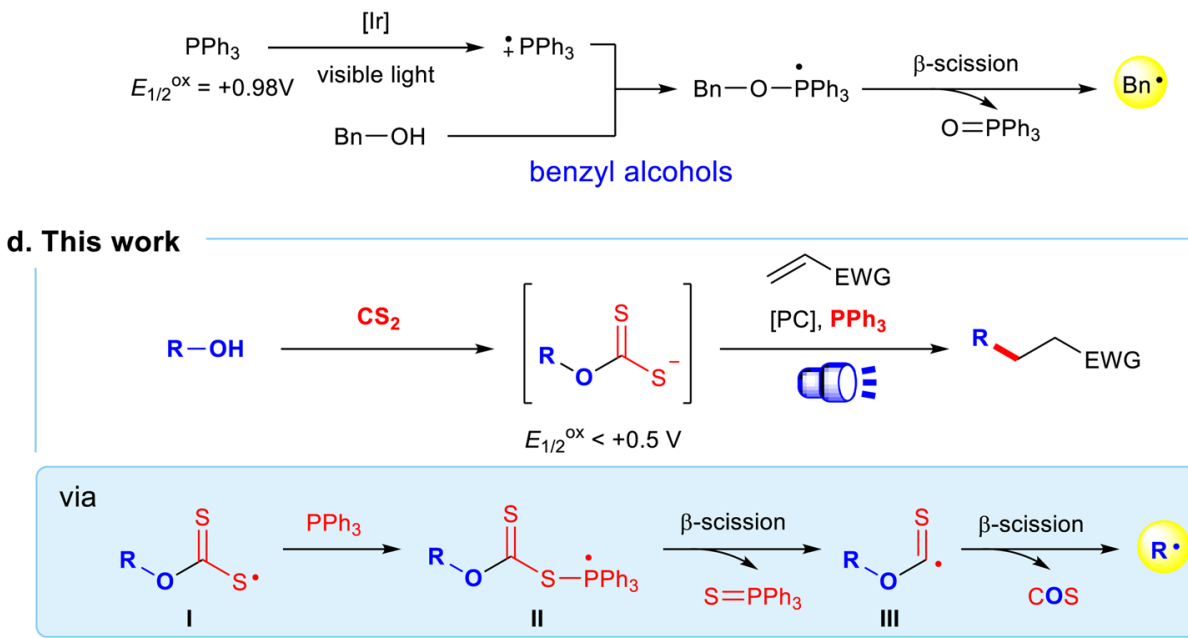

- $1^{\circ}, 2^{\circ} \& 3^{\circ}$ alcohols, including methanol

one-pot procedure selective monodeoxygenation of diols

Fig. 1 Deoxygenative alkyl radical generation from alcohols under visible-light photoredox conditions. a Barton-McCombie deoxygenation; $\mathbf{b}$ visiblelight-mediated deoxygenative radical generation from alcohols; c visible-light-mediated deoxygenation of benzyl alcohols. d Our work. FG functional group, $[\operatorname{lr}]\left[\operatorname{Ir}(\mathrm{dFMeppy})_{2} \mathrm{dtbbpy}_{\mathrm{PF}} \mathrm{F}_{6} \mathrm{PC}\right.$ photocatalyst, EWG electron-withdrawing group. 
Table 1 Optimization and control studies.

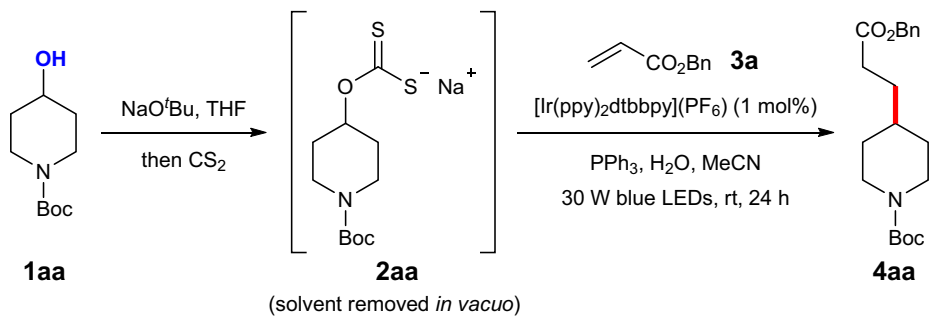

\begin{tabular}{|c|c|c|}
\hline Entry & Variation from optimized conditions & Yield (\%) \\
\hline 1 & None & $92(89)^{b}$ \\
\hline 2 & $\mathrm{P}(\mathrm{OEt})_{3}$ instead of $\mathrm{PPh}_{3}$ & 84 \\
\hline 3 & $\left.\left[\operatorname{lr}\left(\mathrm{dFCF} \mathrm{F}_{3} \mathrm{ppy}\right)_{2} \mathrm{dtbbpy}\right)\right]\left(\mathrm{PF}_{6}\right)(1 \mathrm{~mol} \%)$ & 83 \\
\hline 4 & $\mathrm{Na}_{2} \mathrm{CO}_{3}$ instead of $\mathrm{NaO}^{t} \mathrm{Bu}$ & 0 \\
\hline 5 & No $\mathrm{CS}_{2}$ & 0 \\
\hline 6 & No $\mathrm{PPh}_{3}$ & 0 \\
\hline 7 & No photocatalyst & 0 \\
\hline 8 & No light & 0 \\
\hline 9 & Without $\mathrm{H}_{2} \mathrm{O}$ & 26 \\
\hline 10 & 3a (1.0 equiv) & 66 \\
\hline 11 & $\mathrm{PPh}_{3}(0.20$ equiv $)$ & 20 \\
\hline 12 & $\mathrm{PPh}_{3}(0.20$ equiv $)+$ reductants (2.0 equiv) & $<20$ \\
\hline
\end{tabular}

While Barton-McCombie deoxygenations with xanthate esters have been well established ${ }^{5-7,43,44}$, to the best of our knowledge, the direct use of xanthate salts for radical activations of alcohols has not been reported. Very recently, the strategy of visible-light photoredox-catalyzed phosphoranyl radical fragmentation $45-49$ provides a powerful platform for $\mathrm{C}-\mathrm{O}$ and $\mathrm{C}-\mathrm{S}$ bond homolysis of carboxylic acids $s^{50-56}$ and thiols ${ }^{57-59}$. Inspired by these discoveries, we proposed a masked strategy by switching the redox site from the $\mathrm{C}-\mathrm{O}$ bond to the weaker and SET-amenable C-S bond (Fig. 1d). Treatment of an alcohol with carbon disulfide under basic conditions can readily generate a xanthate anion. We envisioned that the xanthate anion, with low oxidation potential, would undergo SET with an excited state photocatalyst to produce the xanthate radical $\mathbf{I}^{60,61}$. This sulfur-centered radical will subsequently couple with a phosphine source to afford the phosphoranyl radical $\mathbf{I I}^{62-65}$, which then undergoes $\beta$-scission to form the alkoxythiocarbonyl radical III. Theoretical calculations have demonstrated that alkoxythiocarbonyl radicals III extrude carbonyl sulfide (COS) rapidly through $\beta$-scission to produce the corresponding alkyl radicals, including the methyl radical, in three orders of magnitude faster than the loss of carbon dioxide from alkoxycarbonyl radicals ${ }^{66}$. In comparison to the phosphinemediated direct deoxygenation of alcohols developed by Doyle and co-workers (Fig. 1c) ${ }^{35}$, the high reactivity and low voltage gating of xanthate anion will advantage this strategy by energetically more accessible electron transfer and diverse substrate scope other than benzylic alcohols, providing a unique solution for the longstanding challenge on structure generality limitation of alcohols as alkyl radical precursors.

Here we show a visible-light-promoted photoredox coupling of alcohols with electron-deficient alkenes assisted by carbon disulfide and triphenylphosphine. This one-pot protocol enables the selective $\mathrm{C}-\mathrm{O}$ bond homolysis of primary, secondary, and tertiary alcohols to form $\mathrm{C}-\mathrm{C}$ bonds efficiently under mild conditions.

\section{Results}

Optimization of reaction conditions. To evaluate the reaction platform, we first explored the photoredox-catalyzed deoxygenative alkylation of $\mathrm{N}$-Boc-4-hydroxy-piperidine 1aa with benzyl acrylate 3a by a carbon disulfide and triphenylphosphine promoted one-pot protocol. Through extensive condition optimization, we found that deprotonation of $\mathrm{N}$-Boc-4-hydroxypiperidine 1 aa using $\mathrm{NaO}^{t} \mathrm{Bu}$ (1.0 equiv) as a base followed by treatment with carbon disulfide (1.5 equiv) in tetrahydrofuran (THF) readily formed the corresponding sodium xanthate $\mathbf{2 a a}$ (Table 1). After evaporating all volatiles, exposure of a solution of the residue with benzyl acrylate $3 \mathbf{a}$, photocatalyst $[\operatorname{Ir}(\mathrm{p}-$ py $\left.)_{2} \mathrm{dtbbpy}\right]\left(\mathrm{PF}_{6}\right)$, and triphenylphosphine in acetonitrile containing water to a $30 \mathrm{~W}$ blue light-emitting diode (LED) lamp provided the desired alkylation product $4 \mathbf{a a}$ in $89 \%$ isolated yield, along with triphenylphosphine sulfide in $86 \%$ yield indicating a desulfurization process. Meanwhile, the carbonyl sulfur (COS) was detected by gas chromatography-mass spectrometry (Table 1, entry 1). Triethyl phosphite could also be used as the phosphorus source in place of triphenylphosphine, providing the product in $84 \%$ yield (entry 2). Use of [ $\operatorname{Ir}\left(\mathrm{dFCF}_{3}\right.$ ppy) $\left.\left.{ }_{2} \mathrm{dtbbpy}\right)\right]$ $\left(\mathrm{PF}_{6}\right)$ as the photocatalyst resulted in a slightly less efficient reaction (entry 3). Weak bases such as $\mathrm{Na}_{2} \mathrm{CO}_{3}$ were not suitable for the generation of the xanthate salt (entry 4). No reaction was observed without treatment with carbon disulfide, and this observation excluded the direct activation of alcohols by triphenylphosphine under the photoredox conditions (entry 5). Further control experiments conducted in the absence of phosphine, photocatalyst, or light resulted in no product formation, emphasizing the crucial role of all these components in the catalytic cycle (entries 6-8). Significantly lower yield was observed in the absence of water, perhaps due to its role as the proton source (entry 9). Reaction with 1.0 equiv of benzyl acrylate 3a provided the product in $66 \%$ yield (entry 10). Reducing the amount of 

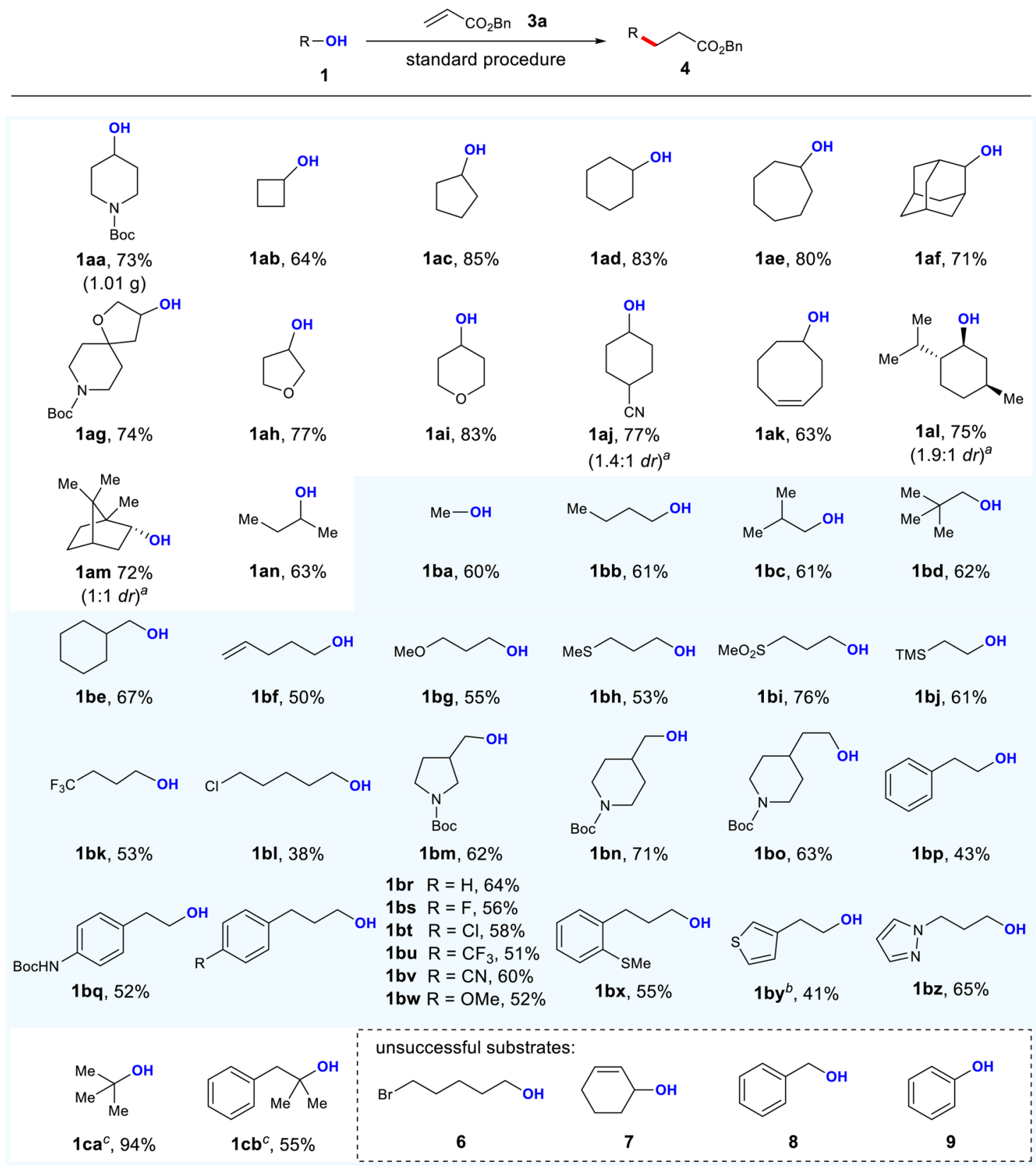

Fig. 2 Scope of alcohols. The standard procedure is as shown in Table 1. Isolated yields are reported. ${ }^{\mathrm{a}}$ The $d r$ was determined by ${ }^{1} \mathrm{H}$ NMR analysis of the product after flash chromatography. ${ }^{\mathrm{b}} 48 \mathrm{~h}$. ${ }^{\mathrm{CNaH}}$ (1.0 equiv) as base. $\mathrm{dr}$ diastereoselectivity ratio.

triphenylphosphine to 0.20 equiv decreased the yield to $20 \%$, correspondingly excluding a triphenylphosphine-initiated/catalyzed pathway (entry 11). In addition, our attempts on using 0.20 equiv of triphenylphosphine combined with stoichiometric reductants failed to increase the yield to exceed 20\% (Supplementary Table 5).

Substrate scope. With the optimized conditions in hand, we investigated the scope of alcohols using this convenient one-pot protocol (Fig. 2). It is noteworthy that the reaction could be run on a $4.0 \mathrm{mmol}$ scale in a Schlenk tube to afford $1.01 \mathrm{~g}$ of the desired product $\mathbf{4 a a}$ ( $73 \%$ yield). Cyclic alcohols (1 $\mathbf{a b}-\mathbf{a j})$, ranging from four- to eight-membered rings, including spirocyclic or bridged motifs, adorned with nitrogen or oxygen atoms, successfully delivered the corresponding products in $64-85 \%$ yields upon Giese reaction with benzyl acrylate 3a. The alkene-retained product was obtained in 63\% yield from cyclooct-4-en-1-ol 1ak, while intramolecular radical cyclization was not observed. This result suggests that the Giese addition of alkyl radical is faster than the 5-exo-trig cyclization $\left(\sim 1 \times 10^{5} \mathrm{~s}^{-1}\right)$ under the reaction conditions ${ }^{67}$. It is noteworthy that natural products $\mathrm{L}$-menthol 1al and (-)-borneol lam reacted smoothly in this transformation, providing the deoxy-alkylated products in $75 \%$ and $72 \%$ yields, respectively. The linear secondary alcohol 1an also provided the desired adduct in $63 \%$ yield. Consistent with the expectation, we were pleased to find that a wide variety of primary alcohols (1ba-bz) including methanol $\mathbf{1 b a}$ were successfully applied in this protocol, furnishing the desired products in moderate-togood yields. Functional groups such as terminal alkenes, ethers, thioethers, sulfones, silanes, trifluoromethyl, chlorides, fluorides, nitriles, Boc-protected amines, phenyls, and heteroarenes were well tolerated, with the deoxygenative alkylated products obtained in $38-76 \%$ yields. Furthermore, by using $\mathrm{NaH}$ as a base for 


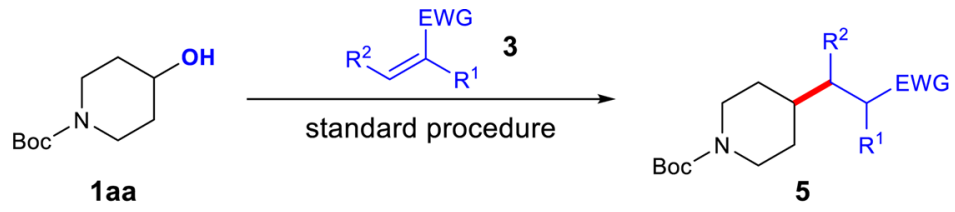

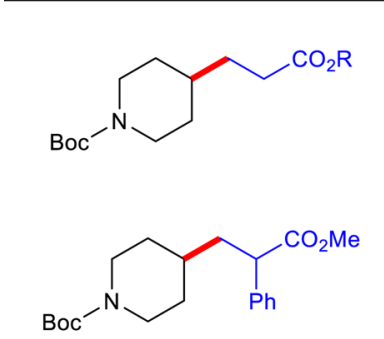

5af, $64 \%$<smiles>CC(=O)OC(C)(C)OC(=O)CC1CCN(C(=O)OC(C)(C)C)CC1</smiles>

5ai, 54\%<smiles>CC(C)(C)OC(=O)N1CCC(CCC#N)CC1</smiles>

5al, $71 \%$ 5aa, $\mathrm{R}=\mathrm{Ph}, 71 \%$

5ab, $R=M e, 63 \%$

5ac, $R=E t, 65 \%$

5ad, $\mathrm{R}={ }^{n} \mathrm{Bu}, 64 \%$<smiles>CC(=O)C(F)CC1CCN(C(=O)OC(C)(C)C)CC1</smiles>

5ag, $88 \%$<smiles>CC(=O)CC(C(C)=O)C1CCN(C(=O)OC(C)(C)C)CC1</smiles>

5aj, $90 \%$<smiles>CC(=O)CCC1CCN(C(=O)OC(C)(C)C)CC1</smiles>

5am, 62\%<smiles>CC(=O)C(C)CC1CCN(C(=O)OC(C)(C)C)CC1</smiles>

5ae, 50\%<smiles>CC(=O)NC(CC1CCN(C(=O)OC(C)(C)C)CC1)C(C)=O</smiles>

5ah, 63\%<smiles>CCOC(=O)C(C(=O)OCC)C(C)C1CCN(C(=O)OC(C)(C)C)CC1</smiles>

5ak, 81\%<smiles>CC(C)(C)OC(=O)N1CCC(CCS(=O)(=O)c2ccccc2)CC1</smiles>

5an, $78 \%$

Fig. 3 Scope of alkenes. The standard procedure is as shown in Table 1. Isolated yields are reported. Cbz benzyloxycarbonyl.

sodium xanthate construction, tertiary alcohols $(\mathbf{1} \mathbf{c a}, \mathbf{1} \mathbf{c b})$ could also be efficiently converted to the corresponding products. In terms of limitations, the current protocol is not applicable to alcohols containing highly electrophilic groups, like alkyl bromides 6. Unfortunately, neither allylic alcohols nor benzylic alcohols were competent substrates $(7,8)$. Deviating from radical conjugate addition, deoxygenation products cyclohexene and toluene were observed in these cases, respectively. Finally, using this protocol, the deoxygenative alkylation of phenol 9 via $\mathrm{Csp}^{2}-\mathrm{O}$ bond cleavage was not successful ${ }^{68-73}$.

To further demonstrate the versatility of this method, a range of electron-deficient alkenes was tested (Fig. 3). As expected, various acrylates were capable acceptors in the reaction (5aa-ad). The reactions of $\alpha$-aryl, $\alpha$-fluoro, or $\alpha$-alkyl substituted acrylates afforded desired products in $50-88 \%$ yields (5ae-ag). Notably, dehydroalanine derivatives participated in the reaction with good efficiency, providing convenient access to unnatural amino acids (5ah, 63\%; 5ai, 54\%). Substitution at the $\beta$-position was tolerated for more electron-deficient alkenes such as maleate and dimethyl ethylidenemalonate, furnishing the expected adducts with high efficiency (5aj, 90\%; 5ak, 81\%). Other electron-deficient alkenes, such as acrylonitrile, enone, and vinyl sulfone, all worked well (5al-an).

Polyols are a ubiquitous structural motif widely found in natural products and pharmaceuticals ${ }^{74}$. The selective transformation of hydroxyl groups in diols and polyols is a frequently encountered challenge ${ }^{42,75-80}$. We hypothesized that a proper base could identify primary, secondary, and tertiary alcohols in diols and polyols based on difference in acidity and steric hindrance, to form the corresponding xanthate salts selectively and realize the chemoselective radical $\mathrm{O}-\mathrm{H}$ bond activation of diols and polyols. To our delight, by using $\mathrm{NaO}^{t} \mathrm{Bu}$ as a base, high selectivity was observed when different diols were employed in the deoxygenative alkylation protocol, which can be summarized in decreasing order of reactivity as follows: primary alcohol > secondary alcohol $>$ tertiary alcohol (Fig. 4). Selective deoxygenation of primary or secondary alcohol in diols (1da-de) over tertiary alcohol was achieved by the one-pot protocol to afford the corresponding products with free hydroxyl groups in 52-83\% yields and $>20: 1$ chemoselectivity. In addition, the deoxygenative transformation showed a predominant preference $(>20: 1$ chemoselectivity) for primary alcohols over secondary ones (1df, 1dg). Mono-deoxylated products were obtained with the symmetrical diols (1dh, 1di). It is worth mentioning that no dialkylation products from these diols were observed under the standard conditions or with double the amount of other components in the protocol. Using 2.0 equiv of $\mathrm{NaO}^{t} \mathrm{Bu}$ resulted in decreased yields of the desired products, while the deoxygenative alkylated compound from $\mathrm{NaO}^{t} \mathrm{Bu}$ was formed.

In addition to the one-pot procedure, the deoxygenative alkylation of alcohols can also be performed in steps (Fig. 5). Sodium cyclohexylxanthate $\mathbf{2 a d}$ was easily isolated as a pale yellow solid in $95 \%$ yield from the reaction mixture at the first step by filtration. Although xanthate salt is hygroscopic, it can be stored for extended periods in a capped container at room temperature without inert gas protection. Compared with freshly prepared salt (85\%), the reaction of xanthate salt $\mathbf{2 a d}$ after storing for 2 weeks provided the deoxygenative alkylated product with no detriment to yield $(84 \%)$.

Synthetic applications. The generality of this method implies applications in the late-stage functionalization of pharmaceuticals and natural products (Fig. 6) ${ }^{81}$. Bronchodilator proxyphylline lea showed good reactivity to deliver the product in $67 \%$ yield. Acetonide D-ribofuranoside and D-glucofuranose derivatives (1eb, lec) were deoxygenated to afford the corresponding 

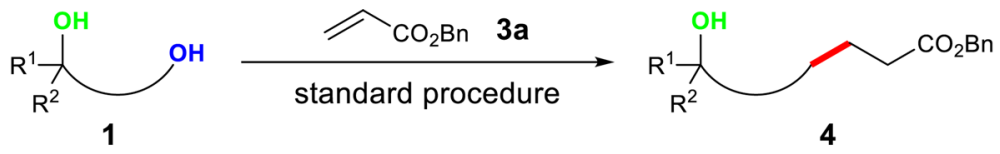<smiles>CC(C)(O)CCO</smiles>

1da, $78 \%$

$(>20: 1 \mathrm{rr})$<smiles>OCC12CC3CC(CC(O)(C3)C1)C2</smiles>

1dd, $52 \%$

(> 20:1 rr)<smiles>CC(CO)[C@H]1CC[C@H]2[C@@H](O)CCC[C@@]12C</smiles>

$1 \mathrm{dg}, 50 \%$

(>20:1 rr)<smiles>OCCC1(O)CCCC1</smiles>

$1 \mathrm{db}, 76 \%$

(> 20:1 rr)<smiles>CC(O)CC(C)(C)O</smiles>

1de, $83 \%$

(> 20:1 rr)<smiles>CC(C)(O)CCC(C)(C)O</smiles>

$1 \mathrm{dh}^{b}, 61 \%$<smiles>OCCC1(O)CCCCC1</smiles>

1dc, $73 \%$

$(>20: 1 \mathrm{rr}$ )<smiles>OCC1CCC(O)CC1</smiles>

$1 \mathbf{d f}^{a}, 64 \%$

(> 20:1 rr)

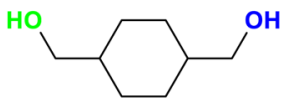

$1 \mathrm{di}^{\mathrm{a}}, 68 \%$

Fig. 4 Selective deoxygenative alkylation of diols. The standard procedure is as shown in Table 1. Isolated yields are reported. ${ }^{a} 48 \mathrm{~h}$. b NaH as base. Unreacted hydroxyl groups are marked in green. $r$ regioselectivity ratio.

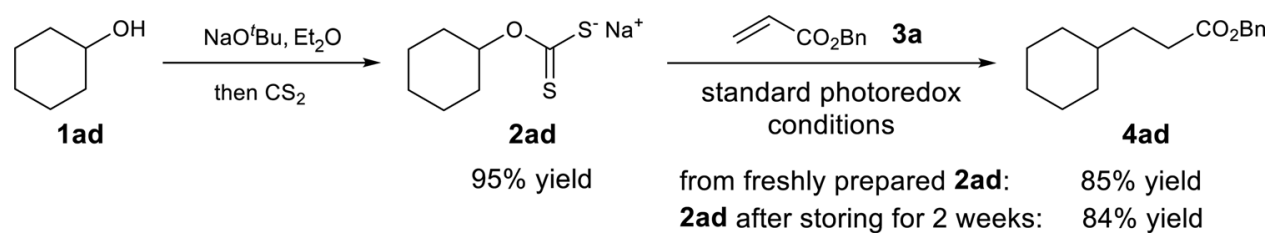

Fig. 5 Preparation and reaction of xanthate salts. Deoxygenative alkylation of alcohols performed in steps.
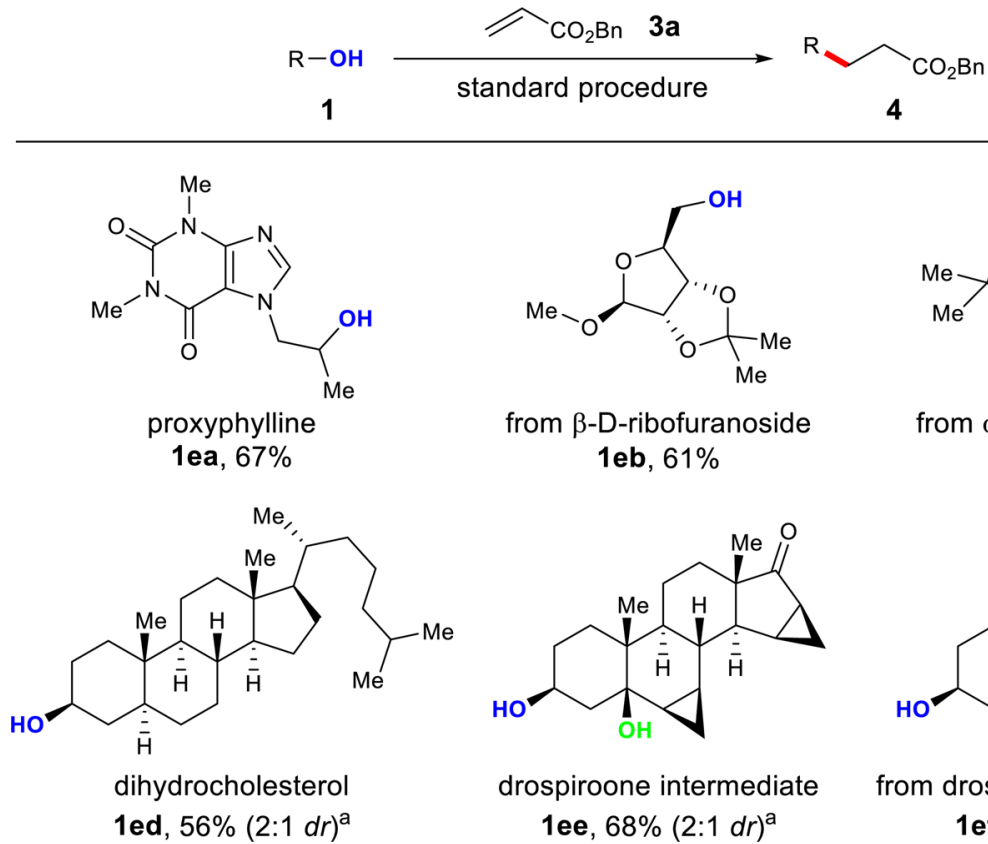<smiles>CO[C@H]1O[C@H](CO)[C@H]2OC(C)(C)O[C@H]12</smiles>

from $\beta$-D-ribofuranoside $1 \mathrm{eb}, 61 \%$

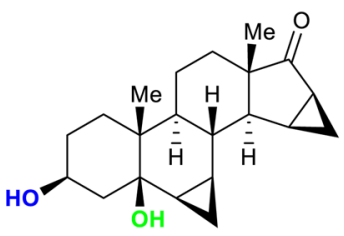

drospiroone intermediate 1ee, $68 \%(2: 1 d r)^{\mathrm{a}}$<smiles>CC1(C)O[C@H]2O[C@H](CO)[C@H]3OC(C)(C)O[C@H]3[C@H]2O1</smiles>

from $\alpha$-D-glucofuranose 1 ec, $54 \%$

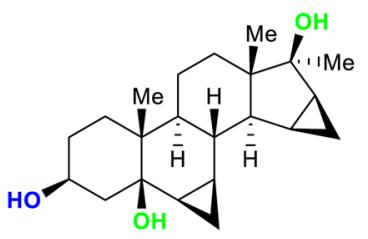

from drospiroone intermediate 1ef, $63 \%(2: 1 d r)^{a}$

Fig. 6 Synthetic applications of the methodology. The standard procedure is as shown in Table 1. Isolated yields are reported. aThe dr was determined by ${ }^{1} \mathrm{H}$ NMR analysis of the product after flash chromatography. 
a.

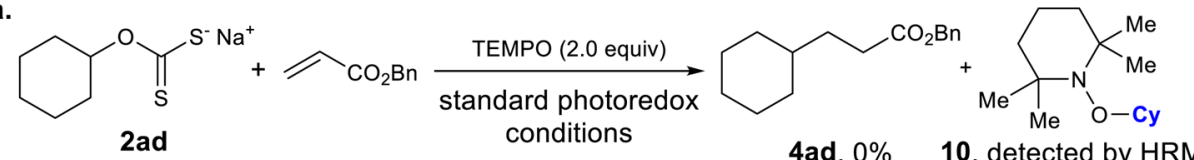

b.<smiles>CC(C)C1CC1CO</smiles><smiles>C=CCCc1ccccc1</smiles>

$12,51 \%$ c.

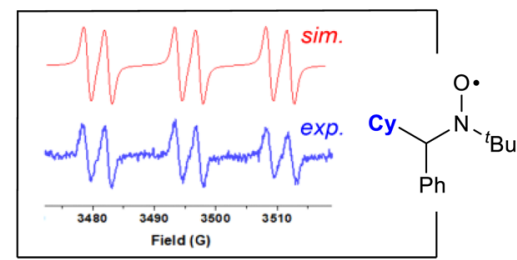

d.

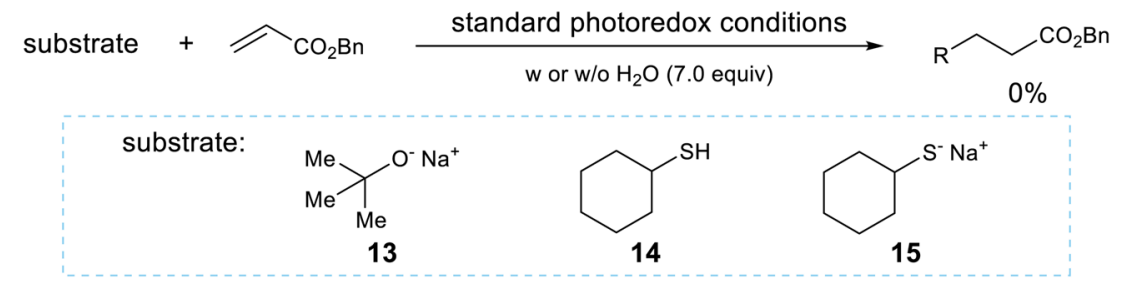

e.

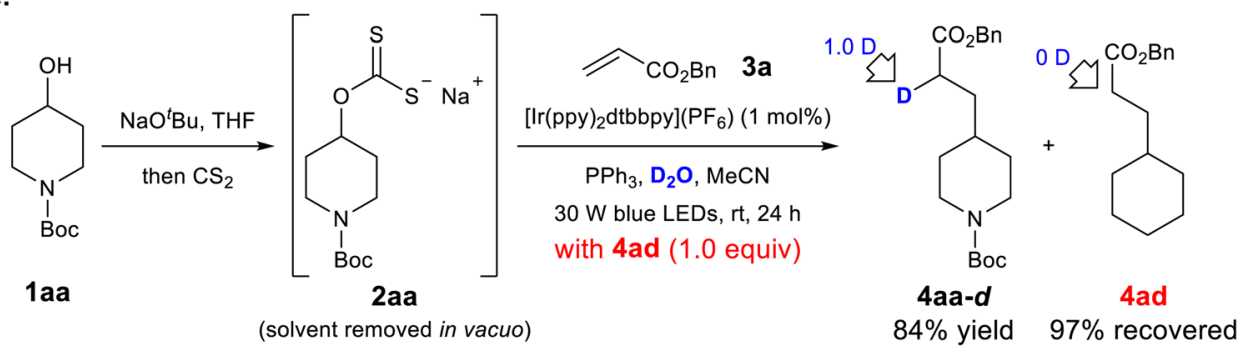

f.

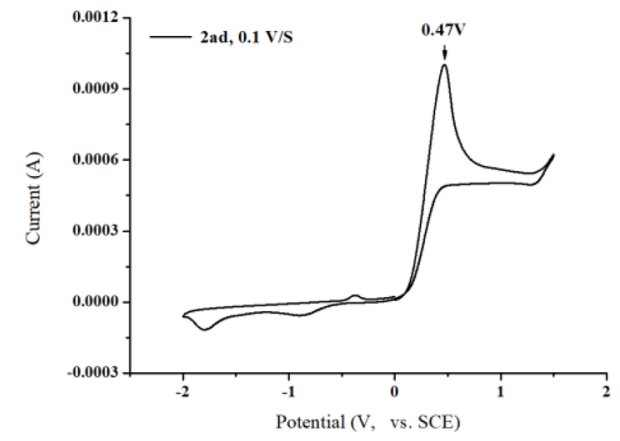

g.

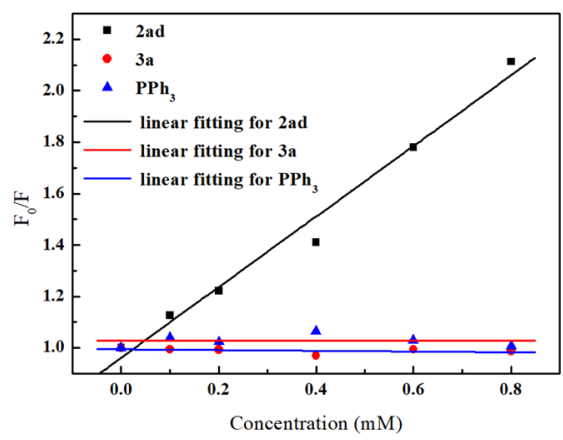

Fig. 7 Probing the mechanism. a Radical trap experiment; b radical clock experiment; $\mathbf{c}$ EPR experiment $\left(g=2.00619, A_{N}=14.9123 \mathrm{G}, A_{H}=3.41209 \mathrm{G}\right)$; d probing the intermediate; e deuterium-labeling experiment; $\mathbf{f}$ cyclic voltammogram; $\mathbf{g}$ Stern-Volmer fluorescence quenching experiment.

alkylated compounds in $61 \%$ and $54 \%$ yields, respectively. Naturally occurring steroids (1ed-ef) were successfully employed, furnishing the desired products in synthetically useful yields. The remarkable selectivity of the reaction was again showcased in alkaloids lee and lef with multiple hydroxyl groups by the selective deoxy-alkylation of secondary alcohol over tertiary alcohols.

Mechanistic studies. To gain insight into the possible reaction pathway, a set of preliminary mechanistic studies have been carried out ${ }^{82}$. The standard photoredox catalysis was completely inhibited in the presence of a stoichiometric amount of TEMPO, and the TEMPO-trapped cyclohexyl radical could be identified by high-resolution mass spectrometry (Fig. 7a). Ring opening was observed when cyclopropanemethanol $\mathbf{1 1}$ was employed, consistent with a radical intermediate (Fig. 7b). Next, electron paramagnetic resonance experiments were carried out with sodium cyclohexylxanthate 2 ad by utilizing PBN as radical scavenger (Fig. 7c). It provided a signal that was consistent with that of cyclohexyl radical according to the literature data ${ }^{83}$. These results provide support for the radical nature of the deoxygenation process. When sodium alkoxide $\mathbf{1 3}$ was directly employed in the photoredox catalysis step, no reaction was observed, excluding the direct deoxygenation of alcohols with triphenylphosphine (Fig. 7d). No reaction was observed with thiol 14 or sodium thiol 15, indicating that $\mathrm{O}, \mathrm{S}$-rearrangement ${ }^{84}$ was not involved in the reaction pathway. When replacing water with deuterium oxide, the reaction of alcohol 1aa in the presence of ester 4ad (1.0 equiv) led to complete deuterium incorporation into the a-position of the corresponding product 4aa-d (Fig. 7e). Meanwhile, no deuterium incorporation was observed in recovered 4ad, indicating that no 


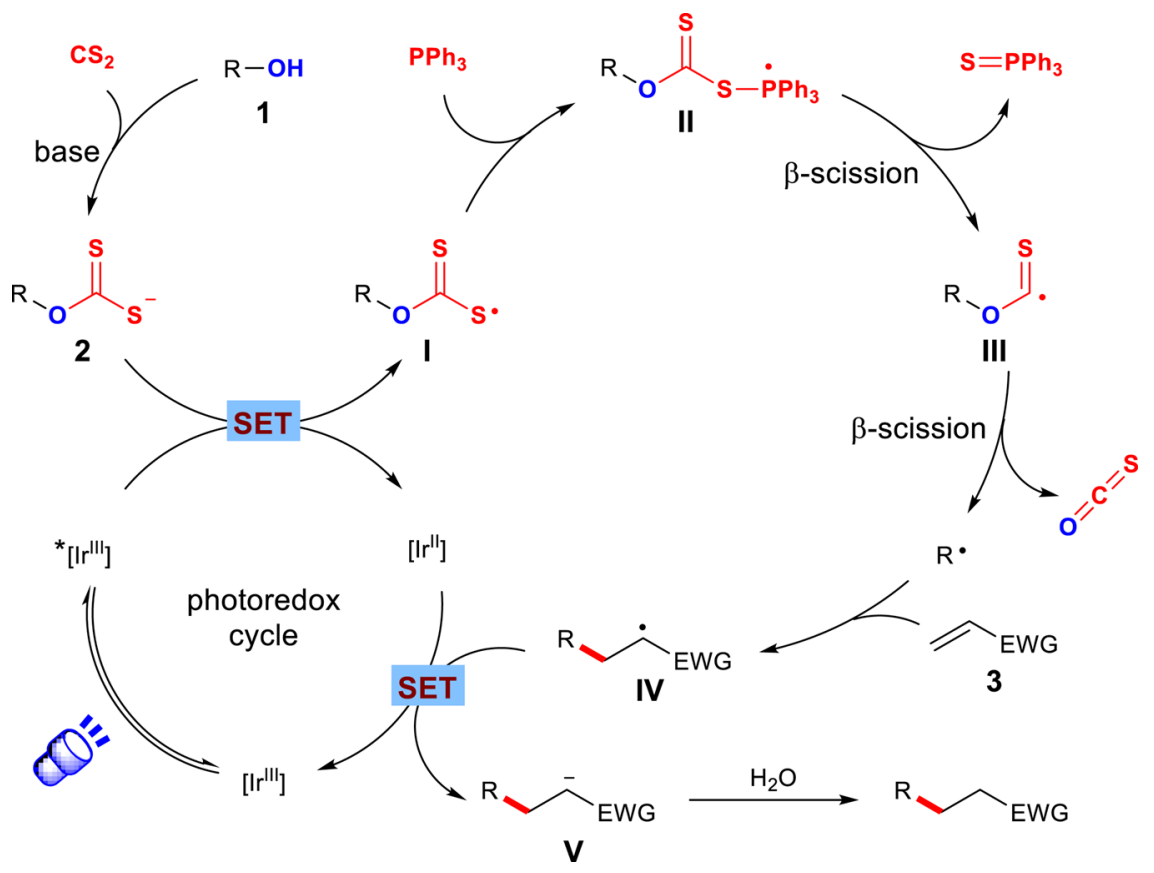

Fig. 8 Proposed reaction mechanism. SET single-electron transfer, $[\operatorname{lr}]\left[\operatorname{lr}(\mathrm{ppy})_{2} \mathrm{dtbbpy}\right]\left(\mathrm{PF}_{6}\right)$.

H/D exchange between the ester product and deuterium oxide via keto-enol tautomerism occurred under the reaction conditions. These results support the intermediacy of a-acyl carbon anion $\mathbf{V}$ in the catalytic cycle (Fig. 8). Oxidation potential of xanthate salt 2ad $\left(E_{1 / 2}{ }^{\mathrm{ox}}=+0.47 \mathrm{~V}\right.$ vs saturated calomel electrode (SCE) in $\mathrm{MeCN})$ measured by cyclic voltammogram shows that it is significantly easier to oxidize compared with triphenylphosphine $\left(E_{1 / 2}{ }^{\text {ox }}=+0.98 \mathrm{~V} \text { vs SCE}\right)^{85}$ (Fig. 7f).

Stern-Volmer fluorescence quenching experiments verified that the excited state ${ }^{*} \operatorname{Ir}(\mathrm{III})$ was quenched effectively by xanthate anion but not by triphenylphosphine or the alkene (Fig. $7 \mathrm{~g}$ ). "Light-dark" experiments confirmed that the reaction required continuous light irradiation. This result and the quantum yield $(\Phi=0.124)$ of the reaction suggest that a radical chain process, based on either a HAT process of an alkyl radical with a xanthate acid or an SET from xanthate anion to intermediate IV, is unlikely.

On the basis of the above experiments and precedent reports, a plausible mechanism was proposed (Fig. 8). Deprotonation of alcohols followed by the reaction with carbon disulfide generates the corresponding xanthate salt 2 . The photoexcited iridium catalyst $\left(E_{1 / 2}{ }^{\text {ox }}\left[{ }^{*} \operatorname{Ir}(\mathrm{III}) / \mathrm{Ir}(\mathrm{II})\right]=+0.66 \mathrm{~V} \text { vs SCE in } \mathrm{MeCN}\right)^{86}$ oxidizes the xanthate anion 2 via SET to form the sulfurcentered radical I. The xanthate radical I couples with the phosphine to afford the phosphoranyl radical II and undergoes $\beta$ scission to form alkoxythiocarbonyl radical III. Fragmentation of the alkoxythiocarbonyl radical III extrudes carbonyl sulfide and produces the corresponding alkyl radical, which subsequently undergoes radical conjugate addition on the acceptor. Reduction of the resulting adduct radical IV $\left(E_{1 / 2}{ }^{\text {red }}=-0.59\right.$ to $-0.73 \mathrm{~V}$ vs SCE in $\mathrm{MeCN})^{87}$ by SET from the $\operatorname{Ir}(\mathrm{II})$ species $\left(E_{1 / 2}{ }^{\text {red }}\right.$ [Ir(III)/ $\operatorname{Ir}(\mathrm{II})]=-1.51 \mathrm{~V}$ vs $\mathrm{SCE}$ in $\mathrm{MeCN})^{86}$ yields the product after protonation and regenerates the ground-state photocatalyst, completing the catalytic cycle.

\section{Discussion}

In conclusion, we have developed a visible-light photoredoxcatalyzed method for the deoxygenative generation of alkyl radicals from various primary, secondary, and tertiary alcohols enabled by inexpensive carbon disulfide and triphenylphosphineassisted $\mathrm{C}-\mathrm{O}$ bond activation via xanthate salt intermediates. A broad range of alkyl groups from alcohols can be efficiently incorporated into various electron-deficient alkenes, and this easily handled one-pot protocol is scalable to the gram level. The two-step sequence is highly chemoselective, demonstrated by the monodeoxygenation of diols and steroids with multiple hydroxyl groups. This method features mild conditions, broad substrate scope, and good functional group tolerance, which can be further applied in the late-stage modification of biologically important complex molecules. The generality of this methodology, as well as the ready availability of the starting materials and reagents, will allow it to become a useful synthetic tool and enjoy extensive use in a range of chemical applications. Further synthetic applications of xanthate salts as alkyl radical precursors in photo-mediated radical processes are underway in our laboratory and will be reported in due course.

\section{Methods}

General procedure for the synthesis of products. In a nitrogen-filled glovebox an oven-dried $5 \mathrm{~mL}$ quartz tube equipped with a magnetic stir bar was charged sequentially with alcohol $1(0.20 \mathrm{mmol})$ and $\mathrm{NaO}^{t} \mathrm{Bu}(19.2 \mathrm{mg}, 0.20 \mathrm{mmol})$, followed by the addition of dry THF $(1.2 \mathrm{~mL})$. The quartz tube was sealed with a septum cap and transferred out of the glovebox, then stirred at room temperature for $30 \mathrm{~min}$. The resulting solution was cooled to $0{ }^{\circ} \mathrm{C}$ followed by addition of $\mathrm{CS}_{2}(22.8 \mathrm{mg}, 19.0 \mu \mathrm{L}, 0.30 \mathrm{mmol})$ via microsyringe, then stirred at $0{ }^{\circ} \mathrm{C}$ for $3 \mathrm{~h}$ before removing the solvent in vacuo. The system was transferred into the glovebox, and $\mathrm{PPh}_{3}(63.0 \mathrm{mg}, 0.24 \mathrm{mmol})$, [ $\left.\operatorname{Ir}(\mathrm{ppy})_{2} \mathrm{dtbbpy}\right]\left(\mathrm{PF}_{6}\right)$ (1.8 $\mathrm{mg}, 1.0 \mathrm{~mol} \%)$, alkene $3(0.40 \mathrm{mmol})$, and $\mathrm{H}_{2} \mathrm{O}(25.2 \mathrm{mg}, 1.4 \mathrm{mmol})$ in $\mathrm{MeCN}(2.0 \mathrm{~mL})$ was added. Then the quartz tube was sealed with a septum cap and transferred out of the glovebox. The reaction mixture was irradiated with a $30 \mathrm{~W}$ blue LED lamp, maintained at a temperature of $26^{\circ} \mathrm{C}$, and stirred for $24 \mathrm{~h}$. After removing the solvent in vacuo, the residue was purified by column chromatography to afford the product. The reaction could also be performed under nitrogen using a Schlenk tube, without the need of a glovebox (see Section 4 in Supplementary Information for details).

\section{Data availability}

The authors declare that the data supporting the findings of this study, including experimental details and compound characterization, are available within the article and its Supplementary Information file. All data are available from the corresponding author upon reasonable request. 
Received: 26 May 2021; Accepted: 26 August 2021;

Published online: 10 September 2021

\section{References}

1. Romero, N. A. \& Nicewicz, D. A. Organic photoredox catalysis. Chem. Rev 116, 10075-10166 (2016).

2. Stephenson, C. R. J., Yoon, T. P. \& MacMillan, D. W. C. (eds) Visible Light Photocatalysis in Organic Chemistry (Wiley-VCH, 2018).

3. Marzo, L., Pagire, S. K., Reiser, O. \& König, B. Visible-light photocatalysis: does it make a difference in organic synthesis? Angew. Chem. Int. Ed. 57, 10034-10072 (2018).

4. Chen, Y., Lu, L.-Q., Yu, D.-G., Zhu, C.-J. \& Xiao, W.-J. Visible light-driven organic photochemical synthesis in China. Sci. China Chem. 62, 24-57 (2019).

5. Crich, D. \& Quintero, L. Radical chemistry associated with the thiocarbonyl group. Chem. Rev. 89, 1413-1432 (2002).

6. McCombie, S. W., Motherwell, W. B. \& Tozer, M. J. In Organic Reactions, Vol. 77 (eds Evans, A. et al.) 161-591 (John Wiley \& Sons, 2012).

7. Zard, S. Z. In Encyclopedia of Radicals in Chemistry, Biology and Materials (eds Renaud, P. \& Sibi, M. P.) 90-108 (John Wiley \& Sons, 2012).

8. Herrmann, J. M. \& König, B. Reductive deoxygenation of alcohols: catalytic methods beyond Barton-McCombie deoxygenation. Eur. J. Org. Chem. 2013, 7017-7027 (2013).

9. Studer, A. \& Curran, D. P. Catalysis of radical reactions: a radical chemistry perspective. Angew. Chem. Int. Ed. 55, 58-102 (2016).

10. Yan, M., Lo, J. C., Edwards, J. T. \& Baran, P. S. Radicals: reactive intermediates with translational potential. J. Am. Chem. Soc. 138, 12692-12714 (2016).

11. Crespi, S. \& Fagnoni, M. Generation of alkyl radicals: from the tyranny of tin to the photon democracy. Chem. Rev. 120, 9790-9833 (2020).

12. Kerr, J. A. Bond dissociation energies by kinetic methods. Chem. Rev. 66 , 465-500 (2002).

13. Nicewicz, D., Roth, H. \& Romero, N. Experimental and calculated electrochemical potentials of common organic molecules for applications to single-electron redox chemistry. Synlett 27, 714-723 (2015).

14. Lackner, G. L., Quasdorf, K. W. \& Overman, L. E. Direct construction of quaternary carbons from tertiary alcohols via photoredox-catalyzed fragmentation of tert-alkyl $N$-phthalimidoyl oxalates. J. Am. Chem. Soc. 135, 15342-15345 (2013).

15. Lackner, G. L., Quasdorf, K. W., Pratsch, G. \& Overman, L. E. Fragment coupling and the construction of quaternary carbons using tertiary radicals generated from tert-alkyl $N$-phthalimidoyl oxalates by visible-light photocatalysis. J. Org. Chem. 80, 6012-6024 (2015).

16. Nawrat, C. C., Jamison, C. R., Slutskyy, Y., MacMillan, D. W. C. \& Overman, L. E. Oxalates as activating groups for alcohols in visible light photoredox catalysis: formation of quaternary centers by redox-neutral fragment coupling. J. Am. Chem. Soc. 137, 11270-11273 (2015).

17. Zhang, X. \& MacMillan, D. W. C. Alcohols as latent coupling fragments for metallaphotoredox catalysis: $\mathrm{sp}^{3}-\mathrm{sp}^{2}$ cross-coupling of oxalates with aryl halides. J. Am. Chem. Soc. 138, 13862-13865 (2016).

18. Guo, L., Song, F., Zhu, S., Li, H. \& Chu, L. syn-Selective alkylarylation of terminal alkynes via the combination of photoredox and nickel catalysis. Nat. Commun. 9, 4543 (2018)

19. Friese, F. W. \& Studer, A. Deoxygenative borylation of secondary and tertiary alcohols. Angew. Chem. Int. Ed. 58, 9561-9564 (2019).

20. Pitre, S. P., Muuronen, M., Fishman, D. A. \& Overman, L. E. Tertiary alcohols as radical precursors for the introduction of tertiary substituents into heteroarenes. ACS Catal. 9, 3413-3418 (2019).

21. Weires, N. A., Slutskyy, Y. \& Overman, L. E. Facile preparation of spirolactones by an alkoxycarbonyl radical cyclization-cross-coupling cascade. Angew. Chem. Int. Ed. 58, 8561-8565 (2019).

22. Ye, Y., Chen, H., Sessler, J. L. \& Gong, H. Zn-mediated fragmentation of tertiary alkyl oxalates enabling formation of alkylated and arylated quaternary carbon centers. J. Am. Chem. Soc. 141, 820-824 (2019)

23. $\mathrm{Li}, \mathrm{H}$. et al. Sequential C-O decarboxylative vinylation/C-H arylation of cyclic oxalates via a nickel-catalyzed multicomponent radical cascade. Chem. Sci. 11, 4904-4910 (2020).

24. Chenneberg, L. et al. Visible light photocatalytic reduction of $O$ thiocarbamates: development of a tin-free Barton-McCombie deoxygenation reaction. Adv. Synth. Catal. 356, 2756-2762 (2014).

25. Vara, B. A., Patel, N. R. \& Molander, G. A. O-Benzyl xanthate esters under Ni/ photoredox dual catalysis: selective radical generation and $\mathrm{Csp}^{3}-\mathrm{Csp}^{2}$ crosscoupling. ACS Catal. 7, 3955-3959 (2017).

26. Wu, J., Bar, R. M., Guo, L., Noble, A. \& Aggarwal, V. K. Photoinduced deoxygenative borylations of aliphatic alcohols. Angew. Chem. Int. Ed. 58, 18830-18834 (2019)
27. Liu, Z.-Y. \& Cook, S. P. Interrupting the Barton-McCombie reaction: aqueous deoxygenative trifluoromethylation of $\mathrm{O}$-alkyl thiocarbonates. $\mathrm{Org}$ Lett. 23, 808-813 (2021).

28. Rackl, D., Kais, V., Kreitmeier, P. \& Reiser, O. Visible light photoredoxcatalyzed deoxygenation of alcohols. Beilstein J. Org. Chem. 10, 2157-2165 (2014).

29. Speckmeier, E., Padie, C. \& Zeitler, K. Visible light mediated reductive cleavage of $\mathrm{C}-\mathrm{O}$ bonds accessing $\alpha$-substituted aryl ketones. Org. Lett. 17, 4818-4821 (2015)

30. Wei, Y., Ben-Zvi, B. \& Diao, T. Diastereoselective synthesis of aryl $C$ glycosides from glycosyl esters via $\mathrm{C}-\mathrm{O}$ bond homolysis. Angew. Chem. Int Ed. 60, 9433-9438 (2021).

31. $\mathrm{Xu}, \mathrm{W}$. et al. Synergistic catalysis for the umpolung trifluoromethylthiolation of tertiary ethers. Angew. Chem. Int. Ed. 57, 10357-10361 (2018).

32. Jin, J. \& MacMillan, D. W. Alcohols as alkylating agents in heteroarene C-H functionalization. Nature 525, 87-90 (2015).

33. McCallum, T., Pitre, S. P., Morin, M., Scaiano, J. C. \& Barriault, L. The photochemical alkylation and reduction of heteroarenes. Chem. Sci. 8, 7412-7418 (2017)

34. Liu, W., Yang, X., Zhou, Z.-Z. \& Li, C.-J. Simple and clean photo-induced methylation of heteroarenes with $\mathrm{MeOH}$. Chem 2, 688-702 (2017).

35. Stache, E. E., Ertel, A. B., Tomislav, R. \& Doyle, A. G. Generation of phosphoranyl radicals via photoredox catalysis enables voltage-independent activation of strong C-O bonds. ACS Catal. 8, 11134-11139 (2018).

36. Bentrude, W. G. Phosphoranyl radicals: their structure, formation, and reactions. Acc. Chem. Res. 15, 117-125 (2002).

37. Walling, C. \& Rabinowitz, R. The reaction of trialkyl phosphites with thiyl and alkoxy radicals. J. Am. Chem. Soc. 81, 1243-1249 (2002).

38. Han, J.-B., Guo, A. \& Tang, X.-Y. Alkylation of allyl/alkenyl sulfones by deoxygenation of alkoxyl radicals. Chem. Eur. J. 25, 2989-2994 (2019).

39. Dieguez, H. R. et al. Weakening C-O bonds: $\mathrm{Ti}(\mathrm{III})$, a new reagent for alcohol deoxygenation and carbonyl coupling olefination. J. Am. Chem. Soc. 132, 254-259 (2010).

40. Suga, T., Shimazu, S. \& Ukaji, Y. Low-valent titanium-mediated radical conjugate addition using benzyl alcohols as benzyl radical sources. Org. Lett. 20, 5389-5392 (2018).

41. Xie, H. et al. Radical dehydroxylative alkylation of tertiary alcohols by $\mathrm{Ti}$ catalysis. J. Am. Chem. Soc. 142, 16787-16794 (2020)

42. $\mathrm{Li}, \mathrm{Z}$. et al. Electrochemically enabled, nickel-catalyzed dehydroxylative crosscoupling of alcohols with aryl halides. J. Am. Chem. Soc. 143, 3536-3543 (2021).

43. Barton, D. H. R. \& McCombie, S. W. A new method for the deoxygenation of secondary alcohols. J. Chem. Soc. Perkin Trans. 1, 1574-1585 (1975).

44. McCombie, S. W., Quiclet-Sire, B. \& Zard, S. Z. Reflections on the mechanism of the Barton-McCombie deoxygenation and on its consequences. Tetrahedron 74, 4969-4979 (2018).

45. Hu, X.-Q., Hou, Y.-X., Liu, Z.-K. \& Gao, Y. Recent advances in phosphoranyl radical-mediated deoxygenative functionalisation. Org. Chem. Front. 7 , 2319-2324 (2020)

46. Pan, D., Nie, G., Jiang, S., Li, T. \& Jin, Z. Radical reactions promoted by trivalent tertiary phosphines. Org. Chem. Front. 7, 2349-2371 (2020).

47. Rossi-Ashton, J. A., Clarke, A. K., Unsworth, W. P. \& Taylor, R. J. K. Phosphoranyl radical fragmentation reactions driven by photoredox catalysis. ACS Catal. 10, 7250-7261 (2020).

48. Shao, X., Zheng, Y., Ramadoss, V., Tian, L. \& Wang, Y. Recent advances in $\mathrm{P}(\mathrm{III})$-assisted deoxygenative reactions under photochemical or electrochemical conditions. Org. Biomol. Chem. 18, 5994-6005 (2020).

49. Maddigan-Wyatt, J. \& Hooper, J. F. Phosphorus compounds as precursors and catalysts for radical C-C bond-forming reactions. Adv. Synth. Catal. 363 924-936 (2021)

50. Zhang, M., Xie, J. \& Zhu, C. A general deoxygenation approach for synthesis of ketones from aromatic carboxylic acids and alkenes. Nat. Commun. 9, 3517 (2018).

51. Zhang, M., Yuan, X.-A., Zhu, C. \& Xie, J. Deoxygenative deuteration of carboxylic acids with $\mathrm{D}_{2} \mathrm{O}$. Angew. Chem. Int. Ed. 58, 312-316 (2019).

52. Jiang, H. et al. Synthesis of dibenzocycloketones by acyl radical cyclization from aromatic carboxylic acids using methylene blue as a photocatalyst. Green Chem. 21, 5368-5373 (2019).

53. Martinez Alvarado, J. I., Ertel, A. B., Stegner, A., Stache, E. E. \& Doyle, A. G Direct use of carboxylic acids in the photocatalytic hydroacylation of styrenes to generate dialkyl ketones. Org. Lett. 21, 9940-9944 (2019).

54. Ruzi, R. et al. Deoxygenative arylation of carboxylic acids by aryl migration. Chem. Eur. J. 25, 12724-12729 (2019)

55. Guo, Y.-Q., Wang, R., Song, H., Liu, Y. \& Wang, Q. Visible-light-induced deoxygenation/defluorination protocol for synthesis of $\gamma, \gamma$-difluoroallylic ketones. Org. Lett. 22, 709-713 (2020).

56. Ruzi, R., Liu, K., Zhu, C. \& Xie, J. Upgrading ketone synthesis direct from carboxylic acids and organohalides. Nat. Commun. 11, 3312 (2020). 
57. Zhang, L. et al. Reductive $\mathrm{C}-\mathrm{C}$ coupling by desulfurizing gold-catalyzed photoreactions. ACS Catal. 9, 6118-6123 (2019).

58. Shi, S., Li, R., Rao, L. \& Sun, Z. A mild, general, and metal-free method for site-specific deuteration induced by visible light using $\mathrm{D}_{2} \mathrm{O}$ as the source of deuterium atoms. Green. Chem. 22, 669-672 (2020).

59. Shi, S. et al. Three-component radical homo Mannich reaction. Nat. Commun. 12, 1006 (2021).

60. Prasanna, R., Guha, S. \& Sekar, G. Proton-coupled electron transfer: transition-metal-free selective reduction of chalcones and alkynes using xanthate/formic acid. Org. Lett. 21, 2650-2653 (2019).

61. de Pedro Beato, E., Mazzarella, D., Balletti, M. \& Melchiorre, P. Photochemical generation of acyl and carbamoyl radicals using a nucleophilic organic catalyst: applications and mechanism thereof. Chem. Sci. 11, 6312-6324 (2020).

62. Denes, F., Pichowicz, M., Povie, G. \& Renaud, P. Thiyl radicals in organic synthesis. Chem. Rev. 114, 2587-2693 (2014).

63. Bentrude, W. G., Hansen, E. R., Khan, W. A., Min, T. B. \& Rogers, P. E. Freeradical chemistry of organophosphorus compounds. III. $\alpha$ vs. $\beta$ scission in reactions of alkoxy and thiyl radicals with tivalent organophosphorus derivatives. J. Am. Chem. Soc. 95, 2286-2293 (2002).

64. Bentrude, W. G., Hansen, E. R., Khan, W. A. \& Rogers, P. E. $\alpha$ vs. $\beta$ Scission in rreactions of alkoxy and thiyl radicals with diethyl alkylphosphonites. J. Am. Chem. Soc. 94, 2867-2868 (2002).

65. Walling, C. \& Pearson, M. S. Some radical reactions of trivalent phosphorus derivatives with mercaptans, peroxides, and olefins. A new radical cyclization. J. Am. Chem. Soc. 86, 2262-2266 (2002).

66. Coote, M. L., Easton, C. J. \& Zard, S. Z. Factors affecting the relative and absolute rates of $\beta$-scission of alkoxythiocarbonyl radicals and alkoxycarbonyl radicals. J. Org. Chem. 71, 4996-4999 (2006).

67. Newcomb, M. In Radicals in Organic Synthesis, Vol. 1 (eds Renaud, P. \& Sibi, M. P.) 327-329 (Wiley-VCH, 2001).

68. Yu, D.-G., Li, B.-J. \& Shi, Z.-J. Exploration of new C-O electrophiles in crosscoupling reactions. Acc. Chem. Res. 43, 1486-1495 (2010).

69. Li, B.-J., Yu, D.-G., Sun, C.-L. \& Shi, Z.-J. Activation of "inert" alkenyl/aryl $\mathrm{C}-\mathrm{O}$ bond and its application in cross-coupling reactions. Chem. Eur. J. 17, 1728-1759 (2011).

70. Cornella, J., Zarate, C. \& Martin, R. Metal-catalyzed activation of ethers via C-O bond cleavage: a new strategy for molecular diversity. Chem. Soc. Rev. 43, 8081-8097 (2014).

71. Tobisu, M. \& Chatani, N. Cross-couplings using aryl ethers via C-O bond activation enabled by nickel catalysts. Acc. Chem. Res. 48, 1717-1726 (2015).

72. Zeng, $\mathrm{H}$. et al. An adventure in sustainable cross-coupling of phenols and derivatives via carbon-oxygen bond cleavage. ACS Catal. 7, 510-519 (2016).

73. Liu, F., Jiang, H.-j, Zhou, Y. \& Shi, Z.-j Direct transformation of arenols based on C-O activation. Chin. J. Chem. 38, 855-863 (2020).

74. Henkel, T., Brunne, R. M., Müller, H. \& Reichel, F. Statistical investigation into the structural complementarity of natural products and synthetic compounds. Angew. Chem. Int. Ed. 38, 643-647 (1999).

75. Shugrue, C. R. \& Miller, S. J. Applications of nonenzymatic catalysts to the alteration of natural products. Chem. Rev. 117, 11894-11951 (2017).

76. Dimakos, V. \& Taylor, M. S. Site-selective functionalization of hydroxyl groups in carbohydrate derivatives. Chem. Rev. 118, 11457-11517 (2018)

77. Sanchez-Rosello, M., Puchlopek, A. L., Morgan, A. J. \& Miller, S. J. Siteselective catalysis of phenyl thionoformate transfer as a tool for regioselective deoxygenation of polyols. J. Org. Chem. 73, 1774-1782 (2008).

78. Fowler, B. S., Laemmerhold, K. M. \& Miller, S. J. Catalytic site-selective thiocarbonylations and deoxygenations of vancomycin reveal hydroxyldependent conformational effects. J. Am. Chem. Soc. 134, 9755-9761 (2012).

79. Jordan, P. A. \& Miller, S. J. An approach to the site-selective deoxygenation of hydroxy groups based on catalytic phosphoramidite transfer. Angew. Chem. Int. Ed. 51, 2907-2911 (2012).

80. Dai, X.-J. \& Li, C.-J. En route to a practical primary alcohol deoxygenation. J. Am. Chem. Soc. 138, 5433-5440 (2016).

81. Cannalire, R. et al. Visible light photocatalysis in the late-stage functionalization of pharmaceutically relevant compounds. Chem. Soc. Rev. 50, 766-897 (2021).
82. Buzzetti, L., Crisenza, G. E. M. \& Melchiorre, P. Mechanistic studies in photocatalysis. Angew. Chem. Int. Ed. 58, 3730-3747 (2019).

83. Panferova, L. I., Zubkov, M. O., Kokorekin, V. A., Levin, V. V. \& Dilman, A. D. Using the thiyl radical for aliphatic hydrogen-atom transfer: thiolation of unactivated C-H bonds. Angew. Chem. Int. Ed. 60, 2849-2854 (2021).

84. Quiclet-Sire, B. \& Zard, S. Z. A practical modification of the Barton-McCombie reaction and radical $O$ - to $S$ - rearrangement of xanthates. Tetrahedron Lett. 39, 9435-9438 (1998).

85. Pandey, G., Pooranchand, D. \& Bhalerao, U. T. Photoinduced single electron transfer activation of organophosphines: nucleophilic trapping of phosphine radical cation. Tetrahedron 47, 1745-1752 (1991)

86. Slinker, J. D. et al. Efficient yellow electroluminescence from a single layer of a cyclometalated iridium complex. J. Am. Chem. Soc. 126, 2763-2767 (2004).

87. Bortolamei, N., Isse, A. A. \& Gennaro, A. Estimation of standard reduction potentials of alkyl radicals involved in atom transfer radical polymerization. Electrochim. Acta 55, 8312-8318 (2010).

\section{Acknowledgements}

We gratefully acknowledge the National Natural Science Foundation of China (21801082), the Fundamental Research Funds for the Central Universities

(2018KFYYXJJ122, 2021GCRC026), and the Innovation and Talent Recruitment Base of New Energy Chemistry and Device (B21003) for financial support. We thank Bin-Qing $\mathrm{He}$ (HUST) for checking the experimental procedures.

\section{Author contributions}

X.W. and H.-M.G. conceived and developed the project. H.-M.G. performed the experiments and collected the data. X.W. wrote the manuscript and both authors commented on the paper.

\section{Competing interests}

The authors declare no competing interests.

\section{Additional information}

Supplementary information The online version contains supplementary material available at https://doi.org/10.1038/s41467-021-25702-4.

Correspondence and requests for materials should be addressed to Xuesong $\mathrm{Wu}$.

Peer review information Nature Communications thanks the anonymous reviewer(s) for their contribution to the peer review of this work.

Reprints and permission information is available at http://www.nature.com/reprints

Publisher's note Springer Nature remains neutral with regard to jurisdictional claims in published maps and institutional affiliations.

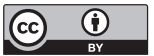

Open Access This article is licensed under a Creative Commons Attribution 4.0 International License, which permits use, sharing, adaptation, distribution and reproduction in any medium or format, as long as you give appropriate credit to the original author(s) and the source, provide a link to the Creative Commons license, and indicate if changes were made. The images or other third party material in this article are included in the article's Creative Commons license, unless indicated otherwise in a credit line to the material. If material is not included in the article's Creative Commons license and your intended use is not permitted by statutory regulation or exceeds the permitted use, you will need to obtain permission directly from the copyright holder. To view a copy of this license, visit http://creativecommons.org/ licenses/by/4.0/.

(c) The Author(s) 2021 